\title{
Burden of Non-Communicable Diseases at a Tertiary Care Hospital of Central Uttar-Pradesh: A Retrospective Study
}

\section{Sham Kumar Gupta1, Mahima1 ${ }^{*}$, Badri Narayan Mishra², Sandip Kumar', Kiran Krishnappa ${ }^{1}$, Sushil Kumar Shukla1}

${ }^{1}$ Department of Community Medicine, Uttar Pradesh University of Medical Sciences, Saifai, India

${ }^{2} \mathrm{R} D$ Gardi Medical College, Ujjain, India

Email: *chandni.mahima9@gmail.com

How to cite this paper: Gupta, S.K., Mahima, Mishra, B.N., Kumar, S., Krishnappa, K. and Shukla, S.K. (2018) Burden of Non-Communicable Diseases at a Tertiary Care Hospital of Central Uttar-Pradesh: A Retrospective Study. Open Journal of Preventive Medicine, 8, 102-108. https://doi.org/10.4236/ojpm.2018.84010

Received: January 31, 2018

Accepted: April 7, 2018

Published: April 10, 2018

Copyright $\odot 2018$ by authors and Scientific Research Publishing Inc. This work is licensed under the Creative Commons Attribution International License (CC BY 4.0).

http://creativecommons.org/licenses/by/4.0/

(c) (i) Open Access

\begin{abstract}
Introduction: Non Communicable Diseases (NCD) has emerged as leading threat to mankind. It approximates to around $70 \%$ mortality burden worldwide. Its mortality burden is more in low \& middle income countries. Most of the premature deaths from NCDs are attributed to modifiable risk factors. In Uttar Pradesh there has been a raise in prevalence of non-communicable diseases in the last two decades. Methodology: Mortality and morbidity data from 1st Jan 2014 to Dec 2016 was obtained from Medical Records Department, UPUMS, Saifai Etawah. The data, thus collected was analyzed by using SPSS 24. Results: Morbidity pattern in UPUMS Saifai reported Blindness and cardiovascular disease (CVD) was leading cause of admission and was increasing year after year. Road traffic acid (RTA), Stroke and CVD were the leading causes of mortality in last 3 years among the patients admitted in tertiary care hospital UPUMS, Saifai, Etawah, U.P., India. Conclusion: Even in rural area prevalence of NCD is at raising trend. RTA, CVD and Stroke were leading causes of death even in rural area.
\end{abstract}

\section{Keywords}

Non-Communicable Diseases, Mortality, Blindness, Stroke, Road Traffic Accidents, Cardiovascular Diseases

\section{Introduction}

Today, Non-Communicable Diseases (NCDs) mainly cardiovascular diseases, cancers, chronic respiratory diseases and diabetes, emerged as leading threat to mankind. It is estimated that 40 million people die in a year because of 
non-communicable diseases, approximating $70 \%$ of all deaths worldwide. Burden of NCDs and its mortality is observed to be more in lower and middle income countries i.e. almost $75 \%$ of all NCD deaths, and $82 \%$ of the people who died prematurely occur in developing countries, which may lead to a huge economical loss and millions of people trapped in poverty in near future [1].

Cardiovascular diseases account for 17.7 million deaths annually, followed by cancers (8.8 million), chronic respiratory diseases (3.9 million), and diabetes (1.6 million). These four groups of diseases account for over $80 \%$ of all premature NCD deaths. The epidemic of NCDs poses catastrophic health consequences for individuals, families and communities, and threatens to triumph over health systems. The economic burdens associated with NCDs make the prevention and control of these diseases a major development issue for the 21st century [1].

Most of these premature deaths from NCDs are attributed to modifiable behavioral risk factors like tobacco use, unhealthy diet, physical inactivity and harmful use of alcohol and metabolic risk factors like raised blood pressure, overweight/obesity, hyperglycemia (high blood glucose levels) and, hyperlipidemia (high levels of fat in the blood) are also attributed to NCDs [1].

In recent decades, rates of CVDs, stroke, and other non-communicable diseases have increased particularly in developed world. Patterns of morbidity and mortality vary greatly between as well as within countries, reflecting inequitable burden of disease among populations disadvantaged by history, circumstances, social and economic conditions [2].

World Health Assembly brought up the WHO Global Action Plan for the Prevention and Control of NCDs 2013-2020 to control the burden of NCDs. The global action plan offers an ideal shift by providing a road map and a menu of policy options for all countries, WHO and intergovernmental organizations, non-governmental organizations (NGOs) and the private sector which, when implemented collectively between 2013 and 2020, will attain 9 voluntary global targets with 25 indicators including that of a $25 \%$ relative reduction in premature mortality from NCDs by 2025 [3].

India shares more than two-third of the total deaths due to NCDs in the South-East Asia Region. Cardiovascular diseases (coronary heart disease, stroke, and hypertension) contribute to $45 \%$ of all NCD deaths followed by chronic respiratory diseases (22\%), cancers (12\%) and diabetes (3\%). The probability of dying between ages 30 and 70 years from four major NCD is $26 \%$ [4]. Uttar Pradesh has also showed a maximum increase in the prevalence of non-communicable diseases to $19 \%$ in 2004 from $7 \%$ in 1995 [5]. Therefore, present study was conducted with the objective to describe the pattern and burden of Non-communicable diseases in a tertiary care hospital of Central Uttar Pradesh.

\section{Methodology}

Uttar-Pradesh University of Medical Sciences is a tertiary level hospital situated 
in Saifai, Etawah, a block of Etawah district of U.P. caters mainly to rural and semi-urban patients, from surrounding districts like Etawah, Mainpuri, Firozabaad, Auraiya, Agra, Gwalior, etc. with a significant number of them being below the poverty line (BPL) income group patients. This government hospital provides all types of health care, diagnostic and laboratory services, in addition to high percentage of referral of high-risk cases and sick patients from other peripheral hospitals. Ethical clearance was obtained prior to the study from Institutional Ethical Committee and administrative permission from medical superintendent of the hospital to retrospectively review the medical files of the subjects.

According to World Health Organization non-communicable diseases, also known as chronic diseases, are not passed from person to person. They are of long duration and generally slow in progression [6]. Study was conducted to identify the morbidity and mortality pattern of non-communicable disease in a tertiary care hospital Uttar-Pradesh University of Medical Sciences, Saifai, Etawah. Data of deceased patient and patients admitted to the hospital had been collected from medical records department of the college for past three years (i.e., from $1^{\text {st } J a n u a r y ~} 2014$ to $31^{\text {st }}$ December 2016). The morbidity and mortality pattern of patients suffering from non-communicable diseases according to the epidemiological factors like (sex, age and rural or urban) was collected from all the different sources of health information system i.e., from medical records department of the hospital, and compiled, classified and rearranged accordingly on the basis of diseases and mortality in form of descriptive manner by the researcher. In case of incomplete data in the computer admission record, files were sought and complete data was obtained. The data of morbidity and mortality pattern of non-communicable disease according to age, sex and rural and urban collected were entered into MS Excel and results were expressed in percentages and proportions by using SPSS 24.

Inclusion Criteria: All case of Non-communicable diseases admitted in our institution within the period of $1^{\text {st }}$ of January 2014 to $31^{\text {st }}$ December 2016.

Exclusion criteria: Patients who left the hospital against medical advice/referred to other hospitals due to any reason, patients whose information was incomplete even after thorough search.

\section{Results}

Among number of cases admitted to the tertiary care hospital from $1^{\text {st }}$ of January 2014 to $31^{\text {st }}$ December 2016 majority were of Blindness (25\%) followed by RTA (21\%), cardio vascular diseases (23\%), COPD and Asthma (9.4\%), neoplasm (8.7\%) and stroke (8.7\%) (Table 1).

Majority of patients suffering from NCDs admitted in the hospital is from rural (64.5\%) and rest is from urban (35.5\%). On studying the distribution of deaths among male and female it was found that male (63.4\%) were more affected from NCDs in respect to female (36.6\%) that too irrespective of age 
Table 1. Distribution of various types of NCDs cases admitted in last three years.

\begin{tabular}{ccc}
\hline Types of NCDs & No. of cases & \% of cases \\
\hline Neoplasm & 1551 & 8.7 \\
Diabetes Mellitus & 857 & 4.8 \\
Blindness & 4406 & 25 \\
Cardio Vascular Diseases & 4081 & 23 \\
Stroke & 1547 & 8.7 \\
COPD and Asthma & 1687 & 9.4 \\
Congenital & 56 & 0.3 \\
RTA & 3675 & 21 \\
Total & 17860 & 100 \\
\hline
\end{tabular}

${ }^{*}$ NCDs: non-communicable diseases; COPD: chronic obstructive pulmonary diseases; RTA: road traffic accidents.

groups. Though, the percentages of mortality seen due to NCDs were found in majority among above 70 years of age (23\%) followed by 55 - 64 (17.5\%) and 45 - 54 years age group (15\%) and then 35 - 44 years i.e., (10\%). Both male and female shows increased prevalence of non-communicable disease with increase of their respective age except slight decrease in deaths is seen in age group $65-69$ years of age (Table 2).

For past three years though one fourth of the cases admitted to the tertiary care hospital because of non-communicable disease are of blindness yet mortality reported due to blindness is zero. With the span of time from the year 2014 to 2016 number of cases admitted because of cardio vascular disease has increased from $19 \%$ to $27 \%$ while mortality has drastically increased by road traffic accidents (RTA), stroke and coronary artery disease (CAD). Cases admitted and mortality seen of chronic obstructive pulmonary disease and asthma has been increased from year 2014 to year 2015 then gradually decreased in 2016. Cases of mortality in rheumatic heart disease are seen in majority in female. Hypertension cases admitted to the hospital has decreased while the case of mortality is seen equally in both male and female. Likewise, cases of neoplasm have been increased and mortality was found more in males with the progress of years (Table 3(a) and Table 3(b)).

\section{Discussion}

As a result of rapid urbanization, industrialization, changing age structure, changing lifestyles, India is facing a growing burden of NCD [7]. Despite of Global Action Plan having 9 voluntary global targets with 25 indicators including that of a 25\% relative reduction in premature mortality from NCDs by 2025 . NCD deaths worldwide now exceed all communicable, maternal and perinatal, nutrition-related deaths combined and represent an emerging global health threat. Deaths due to NCDs are becoming more common in low- and middle-income countries, where the majority of NCD deaths occur and health systems are often 
Table 2. Distribution of deaths according to age for last three years due to NCDs.

\begin{tabular}{cccc}
\hline Age (in years) & Male No. (\%) & Female No. (\%) & Total No. (\%) \\
\hline $0-4$ & $63(3.5)$ & $32(3.0)$ & $32(3.0)$ \\
$5-14$ & $31(1.5)$ & $101(10.0)$ & $63(2.5)$ \\
$15-24$ & $168(9.5)$ & $83(8.0)$ & $269(9.5)$ \\
$25-34$ & $158(9.0)$ & $116(11.5)$ & $241(8.5)$ \\
$35-44$ & $169(9.5)$ & $166(16.5)$ & $285(10.0)$ \\
$45-54$ & $258(14.5)$ & $185(18.0)$ & $424(15.0)$ \\
$55-64$ & $301(17.0)$ & $93(9.0)$ & $486(17.5)$ \\
$65-69$ & $202(11.5)$ & $214(21.0)$ & $295(10.5)$ \\
$\geq 70$ & $425(24.0)$ & $1022(100)$ & $639(23.0)$ \\
TOTAL & $1775(100)$ & & $2797(100)$ \\
\hline
\end{tabular}

* NCDs: non-communicable diseases.

Table 3. (a) Morbidity patterns due to NCDs in last three years; (b) Sex wise mortality patterns due to NCDs in last three years.

(a)

\begin{tabular}{cccc}
\hline No. of cases admitted in a particular year & 2014 & 2015 & 2016 \\
\hline Neoplasms & $401(8.3)$ & $580(10.4)$ & $570(7.2)$ \\
DM & $439(9.1)$ & $301(5.4)$ & $117(1.5)$ \\
Blindness & $1203(25)$ & $1346(24.2)$ & $1857(24)$ \\
CVD & $900(19)$ & $1079(19.4)$ & $2102(27)$ \\
Stroke & $467(9.6)$ & $480(8.65)$ & $600(7.6)$ \\
RTA & $903(19)$ & $1040(18.7)$ & $1732(22)$ \\
COPD and Asthma & $506(10)$ & $702(12.6)$ & $479(11)$ \\
Congenital & $21(0.4)$ & $23(0.4)$ & $22(0.4)$ \\
Total & $4836(100)$ & $5545(100)$ & $7479(100)$
\end{tabular}

*NCDs: non-communicable diseases; DM: diabetes mellitus; CVD: cardiovascular diseases; COPD: chronic obstructive pulmonary diseases; RTA: road traffic accidents.

(b)

\begin{tabular}{|c|c|c|c|c|c|c|c|c|c|}
\hline \multirow{2}{*}{ NCDs } & \multicolumn{3}{|c|}{2014} & \multicolumn{3}{|c|}{2015} & \multicolumn{3}{|c|}{2016} \\
\hline & Male (\%) & Female (\%) & Total (\%) & Male (\%) & Female (\%) & Total (\%) & Male (\%) & Female (\%) & Total (\%) \\
\hline Neoplasms & $5(1.4)$ & $8(4)$ & $13(2.4)$ & $22(3)$ & $13(3)$ & $34(3)$ & $48(6)$ & $13(3)$ & $37(3)$ \\
\hline $\mathrm{DM}$ & $50(14)$ & $30(16)$ & $80(15)$ & $66(9)$ & $35(8.3)$ & $101(8.9)$ & $24(3)$ & $13(3)$ & $37(3)$ \\
\hline Blindness & 0 & 0 & 0 & 0 & 0 & 0 & 0 & 0 & 0 \\
\hline CVD & $85(23.5)$ & $43(23)$ & $128(24)$ & $181(25)$ & $123(31)$ & 304 (27) & 139 (19) & $139(31)$ & $276(25)$ \\
\hline Stroke & $78(21.5)$ & $44(24)$ & $122(22)$ & $178(24)$ & $133(33)$ & 311 (27) & $178(24)$ & $153(34)$ & $281(25)$ \\
\hline RTA & $68(19)$ & $24(13)$ & $92(17)$ & $164(22.3)$ & $55(14)$ & 219 (19) & $258(35)$ & $89(20)$ & $347(31)$ \\
\hline $\begin{array}{c}\text { COPD and } \\
\text { Asthma }\end{array}$ & $70(20)$ & $35(19)$ & 105 (19) & $118(16)$ & $40(10)$ & $158(14)$ & $88(12)$ & $33(7)$ & $121(11)$ \\
\hline Congenital & $2(0.6)$ & $2(1)$ & $4(0.6)$ & $5(0.7)$ & $3(0.7)$ & $8(0.7)$ & $8(1)$ & $11(2)$ & $19(2)$ \\
\hline Total & $358(100)$ & $186(100)$ & $544(100)$ & $734(100)$ & $402(100)$ & $1135(100)$ & $743(100)$ & $451(100)$ & $1118(100)$ \\
\hline
\end{tabular}

${ }^{*}$ NCDs: non-communicable diseases; DM: diabetes mellitus; CVD: cardiovascular diseases; COPD: chronic obstructive pulmonary diseases; RTA: road traffic accidents. 
not equipped to respond [8]. Stroke, CVD and RTA are leading cause of death in our tertiary care hospital.

Blindness, Cardio vascular diseases and Road Traffic Accidents were the most common morbidity found in our institution. Mortality due to NCDs was found to be increasing with increase in age and males are more affected compared to females, similar results were seen in a study conducted by Sharma et al. in Chandigarh [9]. Sharma et al. also found Cardio vascular disease, Diabetes Mellitus and Respiratory disease as a leading cause of death in against of the results of our study. The similar results were also found by Kauser M. M. et al. [10], Holambe V. M. et al. [11], Joshi et al. [12]. These results shows that NCDs burden is raising year by year are common among males. In the study of Pandya R. B. et al. [13] most common age group is 50 - 59 years $(35.88 \%)$ followed by 60 years $(32.06 \%)$ and most common disease among NCDs is diabetes (26.72\%) followed by cardiovascular diseases (25.19\%) which are against of the results in our study [13].

\section{Conclusion}

Our rural tertiary care hospital is reporting more NCD cases than earlier. With the span of time from the year 2014 to present number of cases admitted has drastically increased in case of cardio vascular diseases. Mortality has also drastically increased due to road traffic accidents, stroke and CVD. Deaths due to non-communicable diseases are increasing, among which stroke and ischemic heart disease are appearing as giant killer even in the semi urban areas. Therefore, people should be made aware about risk factors and prevention of NCDs. Also, Government and policy makers should consider the mortality \& morbidity pattern due to NCD which may vary from region to region in order to implement health programmes and policies to make our nation healthier.

\section{Limitations of the Study}

As the study was retrospective, data of the year 2017 was not available from the medical records department at the time collection of data. Therefore, new cases of non-communicable diseases were not studied. As it is a retrospective study, therefore no records of risk factors associated with respective non-communicable diseases were obtained.

\section{References}

[1] WHO (2017) Key Factsheets: Non-Communicable Disease. http://www.who.int/mediacentre/factsheets/fs358/en/

[2] National Collaborating Centre for Infectious Diseases (2016) More than Just Numbers: Exploring the Concept of "Burden of Disease". https://nccid.ca

[3] WHO (2017) Global Action Plan for the Prevention and Control of NCDs 2013-2020. Non-Communicable Diseases and Mental Health. http://www.who.int/nmh/events/ncd_action_plan/en/

[4] WHO (2017) Burden of NCDs and Their Risk Factors in India (Excerpted from Global Status Report on NCDs-2014). 
http://www.searo.who.int/india/topics/ncd_action_plan/en/

[5] Yadav, A.K., Gouda, J. and Ram, F. (2015) Self-Reported Morbidity and Burden of Disease in Uttar Pradesh, India: Evidence from a National Sample Survey and the Million Deaths Study. Journal of Biosocial Science, 48, 1-14. https://doi.org/10.1017/S0021932015000048

[6] WHO (2017) Health Topics: Non-Communicable Diseases. http://www.who.int/topics/non-communicble_diseases/en/

[7] Kujur, M., Kiran, A. and Kumar, M. (2015) Pattern of Non-Communicable Diseases in Patients Attending Medicine Outpatient Department at a Tertiary Care Hospital of Ranchi, Jharkhand. Journal of Evolution of Medical and Dental Sciences, 4, 4676-4681. https://doi.org/10.14260/jemds/2015/676

[8] Jameison, D., et al. (2013) Global Health 2035: A World Converging within a Generation. The Lancet, 382, 1898-1955. https://doi.org/10.1016/S0140-6736(13)62105-4

[9] Sharma, M. and Kumar, D. (2007) Health Care Utilization Pattern for Communicable and Non-Communicable Diseases in a Tertiary Care Health Facility in Chandigarh, India. The International Journal of Health, 7, 1-9.

[10] Kauser, M.M., Kinnera, S., Korrapolu, J., Kalyanam, S.N., Parameshwarappa, K.N. and Afreen, A. (2014) Study of Mortality Pattern in Adults at a Tertiary Care Teaching Hospital in South India. Research and Reviews: Journal of Medical and Health Sciences, 3, 145-149.

[11] Holambe, V.M. and Thakur, N.A. (2014) Mortality Pattern in Hospitalized Patients in a Tertiary Care Centre of Latur. Journal of Krishna Institute of Medical Sciences and University, 3, 111-115.

[12] Joshi, R., Cardona, M., Iyengar, S., Sukumar, A., Raju, C.R., Raju, K.R., et al. (2006) Chronic Diseases Now Leading Cause in Rural India-Mortality Data from the Andhra Pradesh Rural Health Initiative. International Journal of Epidemiology, 35, 1522-1529. https://doi.org/10.1093/ije/dyl168

[13] Pandya, R.B., Sharma, S.K., Siddiqui, S.W. and Gangwar, S. (2016) Study of Patterns of Non-Communicable Disease at Tertiary Care Teaching Hospital. International Journal of Medical Research Professionals, 2, 111-113. 